\title{
VISUALIZAÇÃO E PENSAMENTO GEOMÉTRICO NA GEOMETRIA EM MOVIMENTO
}

\author{
VISUALIZATION AND THINKING GEOMETRIC IN THE GEOMETRY IN MOTION
}

\author{
Janine Freitas Mota \\ Universidade Estadual de Montes Claros - Unimontes, janinemota@gmail.com \\ Rieuse Lopes Pinto \\ Universidade Estadual de Montes Claros - Unimontes, rieuselopes@gmail.com
}

Ronaldo Dias Ferreira

Universidade Estadual de Montes Claros - Unimontes, ronaldodiasferreira@yahoo.com.br

\section{Resumo}

Neste artigo, apresentamos uma discussão sobre uma pesquisa realizada com estudantes da Licenciatura em Matemática, cujo enfoque foi o desenvolvimento da habilidade de visualização e do pensamento geométrico na realização de atividades que contemplam construções geométricas de superfícies tridimensionais com o uso de lápis, papel e ferramenta computacional. Foram elaboradas, aplicadas e analisadas atividades que articularam teoria e prática por meio de investigação, exploração, visualização e construção de superfícies. A articulação entre Álgebra e Geometria e a utilização de seções transversais, presentes nas atividades, buscaram fazer com que os estudantes desenvolvessem a habilidade de visualizar os objetos tridimensionais. $O$ uso da informática educativa, por meio do Winplot, permitiu explorar e formalizar diferentes conceitos geométricos a partir da rotação e translação de figuras, o que facilitou a visualização geométrica com múltiplas representações. A análise qualitativa dos resultados confirmou que houve, por parte dos estudantes, maior capacidade de generalização e que as atividades mostraram uma maneira mais progressista, ou seja, inovadora, de se ensinar Matemática em um ambiente ou em um espaço de prática e de experimentação do conteúdo, visando à compreensão e à interpretação dos tópicos em estudo.

Palavras-chave: Visualização. Pensamento Geométrico. Construções Geométricas. Informática Educativa.

\section{Abstract}

In this article, we present a discussion about a research conducted by students of Degree in Mathematics, which focused the development of the visualization ability and the geometric thought in the carrying out activities that contemplated geometric constructions of three - dimensional surfaces using pencil, paper and computational tools. Activities were 
elaborated, applied and analyzed and these activities articulated theory and practice through activities of investigation, exploration, visualization and construction of surfaces. The articulation between Algebra and Geometry and the use of transversal sections, present in the activities, sought to make the students develop the ability to visualize threedimensional objects. The use of educational informatics through Winplot allowed the exploration and formalization of different geometric concepts, from the rotation and translation of figures, which facilitated the geometric visualization with multiple representations. The qualitative analysis of the results confirmed that the students had a better capacity for generalization and that the activities showed a more progressive and innovative way of teaching Mathematics in situations of practice and experimentation of the content, aiming at understanding and interpretation of the topics that are studied.

Keywords: Preview. Geometric Thought. Geometric Constructions. Educational Informatics.

\section{Introdução}

Percebemos, ao longo de nossa experiência como professores na educação básica e no ensino superior, particularmente em cursos relacionados à área de ciências exatas, as expressivas dificuldades dos estudantes na visualização geométrica de figuras no espaço tridimensional. Tais dificuldades perpassam o ensino básico e chega ao ensino superior, comprometendo a aprendizagem de disciplinas da Matemática Superior como Geometria Analítica, Cálculos Diferencial e Integral, dentre outras.

Diante desse cenário, a questão de investigação da nossa pesquisa foi dividida em 4 (quatro) subquestões: como a habilidade de visualização de certas figuras contribui com o pensamento geométrico? Como a utilização de seções transversais de superfícies podem contribuir para a visualização dessas? Como a articulação entre as representações algébrica e geométrica pode contribuir para o desenvolvimento dos processos de ensino e de aprendizagem de superfícies na disciplina Geometria Analítica? De que forma a utilização de um software contribui para o desenvolvimento da habilidade de visualização de figuras tridimensionais?

Sugerimos uma proposta metodológica cujo objetivo se referia a amenizar as dificuldades de visualização de figuras geométricas, propondo aos estudantes atividades que proporcionavam o desenvolvimento do pensamento geométrico. Nessa proposta, consideramos o uso de softwares que possibilitam aos estudantes experiências diferentes daquelas obtidas no ensino tradicional, que se baseava, frequentemente, no uso do quadro e giz e, quando se referia à visualização geométrica, exposição de figuras do livro didático ou esboços realizados no quadro negro.

A metodologia utilizada no trabalho realizado contemplou os parâmetros de uma sequência didática, baseada no aporte teórico de Zabala (1998), com atividades que articularam teoria e prática, integrando Álgebra e Geometria por meio de investigação, exploração, visualização e construção das superfícies. 
Corroboramos as ideias de Galvão et al. (2017, p. 40) quando afirmam que:

ao ensinar matemática, um desafio que se coloca aos professores é o de adotar uma abordagem de ensino que permita ao aluno uma atitude ativa e condutora da própria aprendizagem. Nesse sentido, levar o aluno a desenvolver na sala de aula uma postura investigativa em relação à matemática, de modo que ele levante conjecturas, possa testá-las, explorar situações propostas, agir por conta própria e talvez descobrir caminhos e validar soluções encontradas.

Essa abordagem investigativa foi utilizada como enfoque da experiência de ensino que possibilitou aos estudantes do primeiro período do curso de Licenciatura em Matemática da Universidade Estadual de Montes Claros (Unimontes) a execução de ações independentes e autônomas frente ao conteúdo proposto.

Foram propostas atividades que privilegiavam o tratamento gráfico, utilizando as seções transversais e as curvas de níveis. As atividades propunham o esboço de gráficos de forma manual (com lápis e papel) e representação desses com o software Winplot, que é gratuito e possibilita o movimento de rotação e translação de figuras no espaço tridimensional.

A análise qualitativa dos resultados evidenciou a forma como os estudantes realizaram as representações gráficas, quais foram as suas reflexões, dúvidas e resultados na integração entre Álgebra e Geometria.

\section{Os processos de ensino e de aprendizagem de geometria: visualização e pensamento geométrico}

A Geometria se constitui de um conjunto de conhecimentos fundamentais para a compreensão do espaço e das figuras que representam objetos utilizados no cotidiano. Entendemos que essa pode proporcionar ao estudante o desenvolvimento de habilidades baseadas na observação e na experiência. Nesse sentido, compartilhamos do entendimento de Ferreira (2010, p. 26) ao afirmar ser

(...) necessário investigar diferentes formas de trabalhar a geometria para atingir um dos principais objetivos educacionais dessa disciplina: a capacidade de abstração espacial a partir de projeções nos espaços unidimensional, bidimensional e tridimensional. Tal competência se incrementa com atividades que possibilitam 0 desenvolvimento da habilidade de visualização para a formação do pensamento geométrico.

Apesar da relevância atribuída a diferentes formas de se trabalhar com a Geometria, para a eficácia do aprendizado, o seu ensino não é realizado de forma satisfatória na educação básica. Algumas pesquisas constatam que o estudo de tópicos de Geometria ainda está ausente ou insuficiente em sala de aula, pois "ainda existem muitos professores que não são formados em Matemática assumindo esta disciplina e mesmo os professores que são matemáticos, muitas vezes, não se sentem capacitados para o ensino de Geometria." (GONÇALVES; LANDO, 2012, p. 386). É uma realidade com que, infelizmente, nos deparamos nos ensinos básico e superior. 
Gravina (1996), ao retratar observações sobre as dificuldades inerentes ao aprendizado da Geometria, apresenta a teoria proposta por Efraim Fischbein ${ }^{1}$ em que o objeto geométrico é tratado como tendo duas componentes: uma conceitual e outra figural. Nessa teoria, a componente conceitual expressa propriedades que caracterizam uma classe de objetos e a componente figural corresponde à imagem mental que associamos ao conceito.

Fischbein caracteriza as figuras geométricas de acordo com sua natureza conceitual e afirma que, no raciocínio matemático, os objetos materiais (sólidos ou desenhos) são modelos materializados de entidades mentais. Por exemplo, os lados, vértices, ângulos de um objeto geométrico não são considerados objetos materiais ou desenhos. Esse autor também ressalta que somente em um sentido conceitual podem-se considerar as entidades geométricas: linhas, retas, círculos, quadrados, triângulos, cubos, etc. Tanto as construções geométricas quanto o conceito são representações gerais e não cópias mentais de objetos concretos; e pontos (objetos de dimensão zero), linhas (objetos unidimensionais), planos, (objetos bidimensionais) não existem na realidade empírica, ou seja, apenas os objetos reais são necessariamente tridimensionais.

Para compreender o desenvolvimento do pensamento geométrico, dentre os diversos estudos sobre o ensino e a aprendizagem da Geometria, ressaltamos o modelo desenvolvido por Pierre M. Van Hiele e sua esposa, Dina Van Hiele Geldof, ambos professores holandeses que, por meio da própria experiência em sala de aula, interessaram-se por estudar esse campo de conhecimento. Para desenvolver a teoria do desenvolvimento do pensamento geométrico na tese de doutorado em Matemática e Ciências Naturais, o casal verificou por quais motivos os alunos dominavam a maior parte dos conteúdos curriculares, mas apresentavam dificuldades na aprendizagem de geometria. Ao refletir sobre essa questão, Van Hiele (1957) constatou a existência de diferentes níveis de desenvolvimento que compõem o pensamento geométrico. De acordo com esse autor, o pensamento geométrico se baseia no conhecimento de um modelo do espaço tridimensional que tem início nas primeiras interações da criança com objetos do mundo físico e é sistematizado à medida que os conteúdos geométricos são estudados.

Dessa forma, esse autor propôs um modelo teórico que consiste na evolução da aprendizagem em geometria a partir de fases hierárquicas de conhecimento. Essa teoria é formada por cinco níveis de desenvolvimento do pensamento geométrico (visualização, análise, dedução informal, dedução formal e rigor), que se inicia a partir da compreensão dos objetos geométricos pelo seu aspecto global, concluindo-se no estudo de diferentes sistemas axiomáticos. Cada nível possui características específicas, como seu próprio vocabulário, além de relações com os objetos geométricos que divergem de um nível para outro. O progresso entre os níveis ocorre por meio de uma sequência hierárquica, em que o aluno passa de um nível mais elementar para um mais elaborado, ou seja, ao estudar conceitos geométricos, por meio de atividades bem planejadas e previamente elaboradas pelo professor, um estudante progredirá com mais facilidade do que um aluno que não teve as mesmas condições. Nessa teoria, o aluno que estuda objetos matemáticos de

\footnotetext{
${ }^{1}$ The theory of figural concepts. In: Educational Studies in Mathematics, 24/2, Kluwer Academic Publishers, 1993, p. 139-162.
} 
forma sistemática, poderá dominar o processo dedutivo, desenvolver demonstrações, estabelecer comparações de axiomas e teoremas de diferentes sistemas, que são características do quarto nível e do quinto nível de pensamento geométrico.

Para Van Hiele (1957), no primeiro estágio, denominado nível de visualização, os alunos reconhecem as figuras geométricas pelas suas aparências e não por suas propriedades ou características próprias. Por exemplo, quando o estudante identifica um quadrado ou um retângulo, mas não considera o quadrado como retângulo, visto que divergem em suas aparências.

Embora o modelo de Van Hiele seja mais utilizado no nível básico de ensino, entendemos que também pode ser utilizado no nível superior, de maneira similar, para contribuir com estratégias para minimizar as dificuldades apresentadas na aprendizagem de tópicos de geometria. Neste trabalho, tratamos especialmente dos 3 (três) primeiros dos 5 (cinco) níveis de Van Hiele, isto é, dos níveis de reconhecimento, análise e abstração, com o tratamento gráfico das figuras espaciais.

O termo visualização é empregado por diversos autores com base nas similaridades e diferenças encontradas nas várias definições daquele na literatura. Com base no estudo das definições de visualização pesquisadas, entendemos que essa é uma aptidão que está relacionada com a habilidade de gerar uma imagem mental, promover diversas transformações com objeto e reter alterações produzidas sobre ele. Entre algumas definições sobre visualização, destacamos a de Frota e Couy (2009, p.4), para quem

visualizar é um processo de criar e/ou interpretar e registrar ideias e imagens, que por sua vez podem desencadear novas ideias e imagens. Nessa perspectiva, a visualização é parte do conjunto de processos de fazer Matemática, ao lado da intuição, criação, abstração, formalização, comunicação, entre outros, podendo ao mesmo tempo impulsionar o desenvolvimento de tais processos.

Nas atividades propostas, buscou-se, primeiramente, o reconhecimento de espaços e propriedades das figuras, partindo de suas seções transversais, de forma a fazer com que o estudante pudesse familiarizar-se com as formas geométricas, figuras e movimentos dessas possibilitados pelo uso do software Winplot, antes de atingir a capacidade do uso da simbologia e do formalismo algébrico.

\section{Potencialidade dos softwares nos processos de ensino e de aprendizagem da matemática}

Os softwares de Geometria Dinâmica proporcionam novas possibilidades de exploração e experimentação de estratégias didáticas a partir do movimento produzido em construções geométricas. Essa estrutura dinâmica proporciona a visualização das construções, de seus elementos e propriedades, tanto no espaço bidimensional quanto no tridimensional. Os softwares gráficos para ensino e aprendizagem de Matemática possibilitam a visualização das distintas representações de um objeto simultaneamente e, por conseguinte, a transição entre as múltiplas representações. 
A utilização de softwares educativos na área de Matemática tem evoluído de maneira significativa em função da qualidade dos produtos disponibilizados no mercado e do seu reduzido custo. Alguns professores, pesquisadores e profissionais da área de tecnologia contribuem para a elaboração de softwares livres e para o desenvolvimento de novas ferramentas capazes de torná-los mais atraentes, eficazes e operativos para sua utilização no contexto educacional.

Assim como ressaltam Melo e Fireman (2016, p. 14) em sua experiência de ensino:

a utilização de softwares relacionados ao ensino e aprendizagem deve-se à capacidade de a maioria executar os mais diversos conteúdos matemáticos de forma dinâmica, fazendo com que o aluno enxergue o conteúdo sob diversos ângulos, aguçando seu espírito de observação e de pesquisa. (...) No entanto, é preciso que sua a escolha pelo docente seja resultado de um planejamento didático-pedagógico, analisado com cuidado para que se possa atingir aos objetivos de aprendizagem de determinado conteúdo matemático.

Bairral (2012, p. 15-16) lembra que "a garotada não manuseia apenas controles remotos, ela envia mensagens, cria códigos variados, busca, baixa, clica, arrasta, maximiza, minimiza, etc." e está conectada com o mundo o tempo todo. Nesse sentido, a escola tem que se adequar a esse novo contexto, buscando a apropriação de novas tecnologias como auxílio na produção de um novo cenário na relação ensino e aprendizagem. A aprendizagem da Matemática em ambientes informatizados depende de ações que caracterizam o fazer, experimentar, interpretar, visualizar, induzir, conjecturar, abstrair e demonstrar o que está aprendendo.

Borba et al. (2014) apresentam discussões acerca do uso das tecnologias na Educação Matemática no Brasil, sugerem a integração de informática no ensino da Matemática e mostram também a complexidade dessa integração. As dificuldades em desenvolvê-las urgem por diversos fatores estruturais e/ou pedagógicos, como, por exemplo: dificuldade de acesso às ferramentas (computadores, calculadoras, internet, softwares) e dificuldade na elaboração de recursos pedagógicos como sequências didáticas, criação ou adaptação de atividades, adequação curricular, dentre outros.

Nesse contexto, cabe ao professor buscar procedimentos metodológicos que utilizem essas novas tecnologias, a fim de propiciar uma maior interação e envolvimento com as múltiplas possibilidades existentes, buscando a apropriação de novos conhecimentos, habilidades e atitudes advindas dessa nova realidade. A utilização de recursos de informática no ensino da Matemática possibilita uma visualização satisfatória dos conceitos matemáticos, por parte dos estudantes, o que deverá contribuir com a compreensão de significados (GODINO; BATANERO; FONT, 2007). A partir disso, os estudantes podem desenvolver a habilidade de solucionar diversas situações-problema que envolvem tais conceitos, por meio da utilização de distintas representações, conforme destaca Duval (2012, p.270):

é essencial, na atividade matemática, poder mobilizar muitos registros de representação semiótica (figuras, gráficos, escrituras simbólicas, linguagem natural, etc.) no decorrer de um mesmo passo, poder escolher um registro no lugar de outro. [...] O recurso a muitos registros parece 
mesmo uma condição necessária para que os objetos matemáticos não sejam confundidos com suas representações e que possam também ser reconhecidos em cada uma de suas representações.

\section{As atividades}

As atividades propostas possibilitaram ao estudante 0 desenvolvimento do pensamento geométrico no trabalho com superfícies tridimensionais, especialmente, no traçado de seus gráficos. Por exemplo, para o traçado do gráfico da função definida implicitamente pela equação $x+y-2=0$, estabelecemos a sequência descrita no Quadro1.

QUADRO 1: sequência de construção do gráfico da função definida implicitamente pela equação $x+y-2=0$.

Considere a equação $x+y-2=0$

a) Como será a representação gráfica dessa equação considerando o $\mathfrak{R}^{2}$ (plano xy)? Faça o esboço do gráfico.

b) Essa equação é uma equação de plano. Dê os valores dos parâmetros presentes nessa equação.

c) Vamos descobrir como se dá a representação gráfica no $\mathfrak{R}^{3}$. Siga os passos:

c.1) Complete a equação introduzindo a variável $z$.

c.2) Dê as coordenadas dos pontos de interseção do gráfico da função definida implicitamente pela equação $x+y-2=0$ no $\mathfrak{R}^{2}$, (que será uma reta), com os eixos x e y no sistema tridimensional.

c.3) Esboce o gráfico, abaixo, usando os interceptos.

Fonte: Dados da pesquisa

$\mathrm{Na}$ Figura 1, apresentamos exemplos de esboços, feitos no papel, pelos estudantes.

FIGURA 1 - Protocolo extraído do caderno de atividades de um dos estudantes.

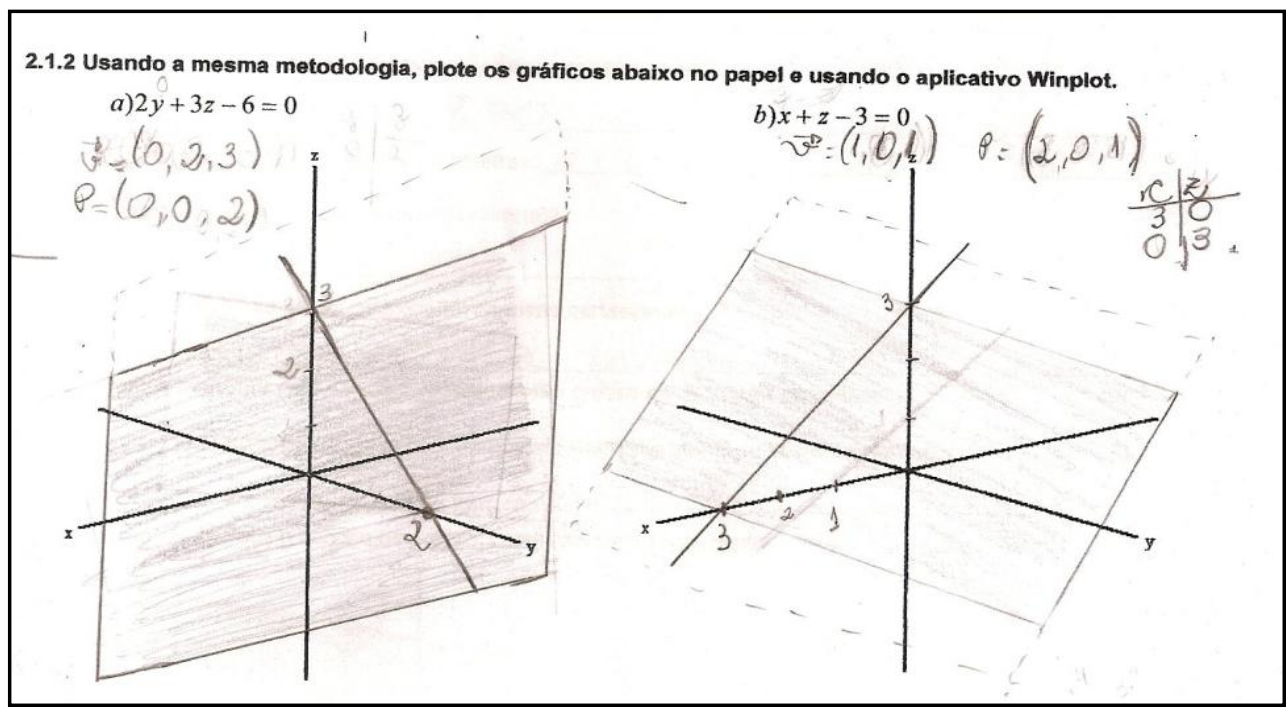

Fonte: Dados da pesquisa 
$\mathrm{Na}$ sequência, propusemos que o gráfico fosse plotado no software Winplot. $\mathrm{Na}$ Figura 2, apresentamos um dos resultados de comandos executados nas telas do Winplot:

FIGURA 2 - Representações gráficas da função definida implicitamente pela equação $x+y-2=0$ no plano cartesiano e no espaço cartesiano, respectivamente.

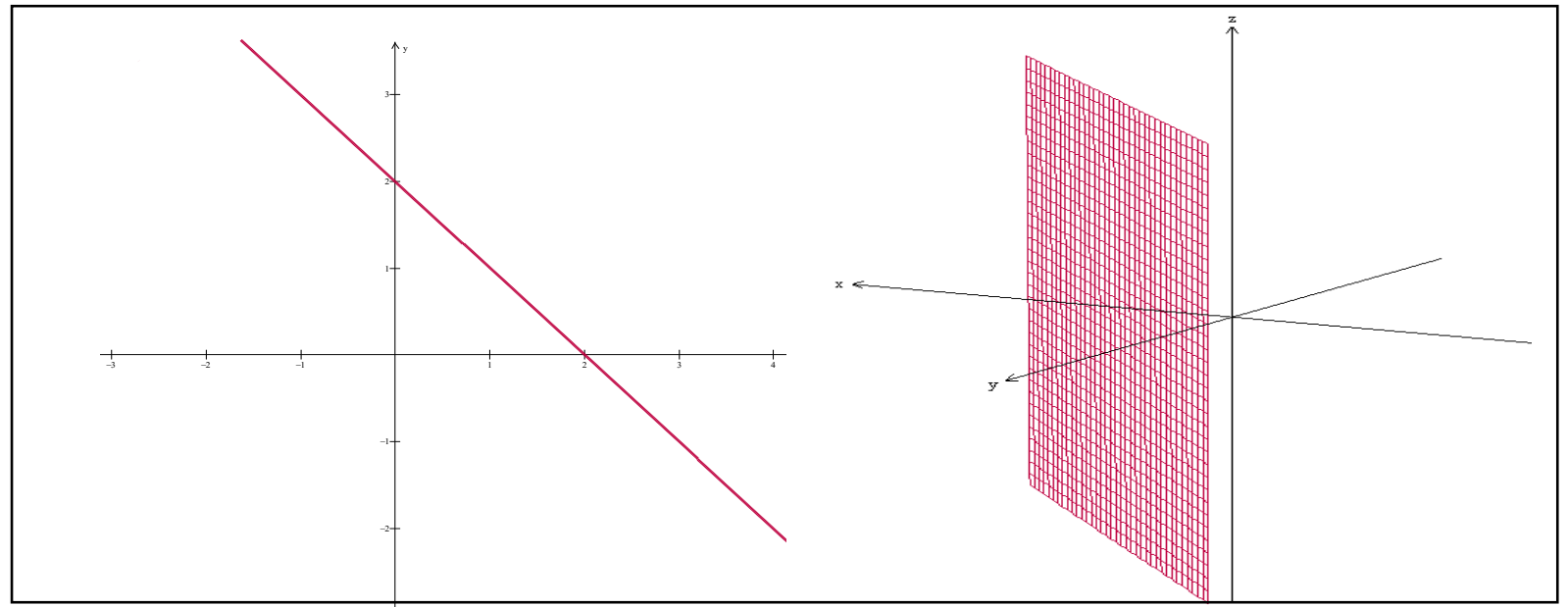

Fonte: Software Winplot

A partir da plotagem do gráfico no software Winplot, foram apresentadas questões acerca da representação gráfica do plano proposto no espaço tridimensional, explorando a interação da parte algébrica com a parte gráfica. A seguir, apresentamos algumas das questões propostas.

QUADRO 2: sequência de atividades

Analisando a representação gráfica do plano, no espaço tridimensional, determinado pela função definida implicitamente pela equação $x+y-2=0$, responda:

a) O plano proposto intercepta quais eixos?

b) Quais os pontos de interseção entre o plano e os eixos coordenados?

c) Qual(is) são a(s) variável(is) livre(s) na equação, considerando o espaço tridimensional?

d) O plano proposto está contido em quais octantes?

d) O plano proposto está paralelo a quais eixos?

\section{Fonte: Dados da pesquisa}

Outra atividade proposta consistia em plotar a figura composta pelos planos definidos implicitamente pelas equações $x=1 ; y=1 ; z=1$, no primeiro octante, em que o estudante visualiza a seguinte imagem no Winplot, conforme a Figura 3. 
FIGURA 3 - Superfície composta por planos paralelos aos planos coordenados.

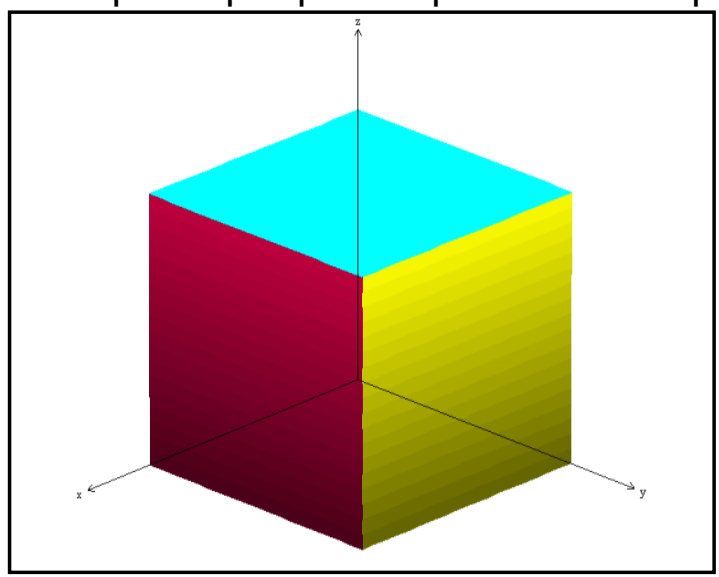

Fonte: Software Winplot

Nessa atividade, foi esperada uma familiaridade com os planos esboçados nas atividades anteriores e que o estudante tivesse sucesso na montagem dos sólidos no espaço tridimensional, tanto utilizando a ferramenta computacional, quanto fazendo o esboço manual. Inicialmente, foi proposto na atividade o esboço manual dos sólidos e em seguida foi solicitada a plotagem desses, usando o software. O esboço manual realizado para esse e outros sólidos, propostos na atividade, é apresentado a seguir.

FIGURA 4 - Planos definidos implicitamente pelas funções $x=1 ; y=1 ; z=1$; $x+y=2 ; z=5$. Protocolo extraído do caderno de atividades de um dos estudantes.

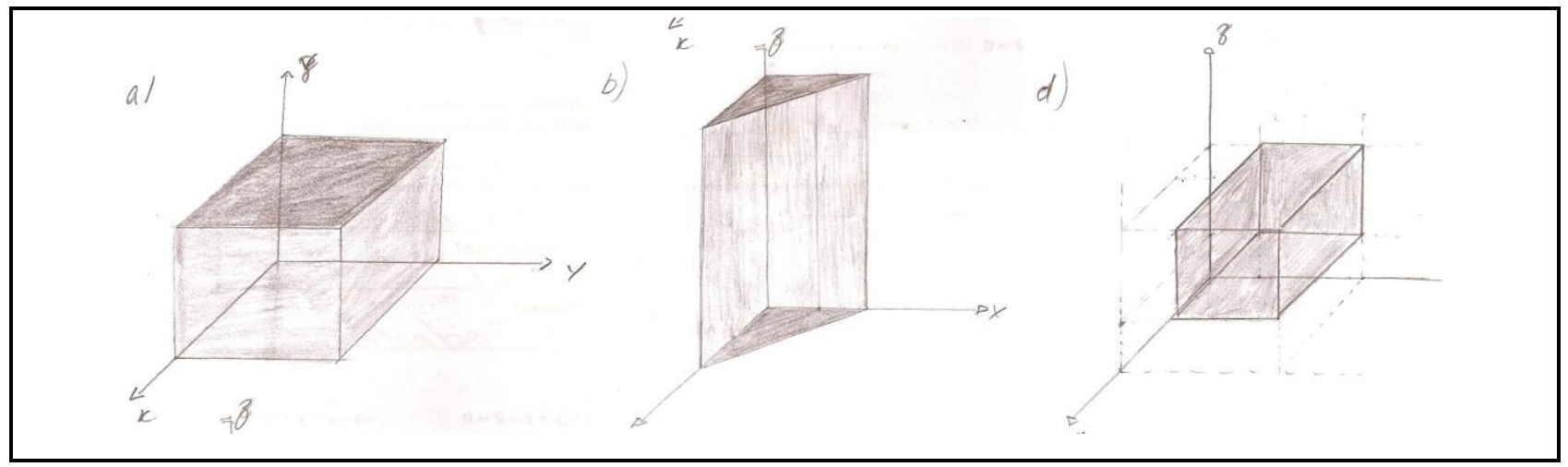

Fonte: Dados da pesquisa

Essa atividade exigiu um pouco mais de raciocínio e pensamento dos estudantes, pois além de dominar bem a utilização do software, esses tiveram que analisar quais planos formavam tais figuras e quais seriam as definições dos limites de cada plano plotado.

Buscamos um referencial teórico para a elaboração das atividades, destacando pesquisas produzidas no Brasil que tratam das dificuldades de visualização de figuras tridimensionais, tendências didático-pedagógicas para o ensino de Geometria e propostas de atividades de Geometria com o uso de recursos computacionais. Utilizamos a proposta 
de desenvolvimento da habilidade de visualização proposto por Villarreal (1999, p.37), citando Zimmermann e Cunningham ${ }^{2}$, assinalando que

visualização em Matemática é o processo de formar imagens (seja mentalmente, com lápis e papel, seja com ajuda de tecnologia) e empregálas com a finalidade de atingir uma maior compreensão matemática e estimular o processo de descobrimento matemático.

Assim, desenvolvemos atividades que envolveram as mídias "lápis e papel" e o software no processo de formar imagens, a fim de possibilitar ao estudante uma maior compreensão dos aspectos algébricos. O planejamento foi fundamentado no referencial teórico pesquisado, destacando as possíveis interações entre sujeitos, pesquisadores e foco do estudo. As estratégias de solução das atividades foram analisadas de forma a verificar as contribuições cognitivas que essas trariam aos sujeitos da pesquisa e que conjecturas poderiam ser levantadas e validadas. Foram exploradas questões acerca da representação gráfica das superfícies no espaço tridimensional; de suas seções transversais; identificação das curvas de níveis e esboço manual dessas; exploração de equações de outras superfícies com as mesmas características.

\section{Análise dos resultados obtidos}

Durante a realização das atividades, os estudantes se depararam com dificuldades variadas, relativas ao gerenciamento do computador, domínio das ferramentas do software compreensão dos conceitos relacionados às superfícies: identificação das equações, de seus parâmetros, das variáveis livres, da interseção das superfícies com os eixos coordenados, dentre outros aspectos; isso por falta de conhecimentos básicos da Álgebra ou da Geometria. Após fazerem a representação das superfícies usando o Winplot, os estudantes fizeram comparações com 0 que haviam desenhado manualmente. Com o uso do software, puderam movimentar a figura, visualizando-a por meio de várias vistas (pela direita, esquerda, de cima, de baixo). Assim, ficaram evidentes as vantagens didáticas que o uso dos computadores oferece nesse cenário, conforme discutido por Borba et al. (2014).

Assim, os estudantes puderam mobilizar, de forma especial, na execução das atividades propostas, 3 (três) primeiros dos 5 (cinco) níveis de Van Hiele: 1) Visualização ou reconhecimento, pois os estudantes puderam ter uma percepção global sobre as superfícies em estudo, fazendo observações acerca delas, realizando comparações entre essas e fazendo associações dos nomes das superfícies e às suas representações algébricas e geométricas; 2) Análise, uma vez que os estudantes começaram a perceber conceitos geométricos, fazendo análise das características das superfícies em estudo, observando-as como um todo, mas identificando cada uma de suas partes (nesse caso, as seções transversais) e suas propriedades geométricas, utilizando as experimentações realizadas com a ajuda do software; 3) Dedução informal ou classificação, já que os estudantes tiveram a oportunidade de fazer inter-relações entre as propriedades de cada

\footnotetext{
${ }^{2}$ ZIMMERMANN, W. Visual Thinking in Calculus. In: ZIMMERMANN, W. CUNNINGHAM, S. Visualization in teaching and learning Mathematics. Washington, DC: Mathematical Association of America, 1991, p. 127-138.
} 
superfície e compará-las umas com as outras, aumentando sua capacidade de abstração espacial a partir de projeções nos espaços do unidimensional para o bidimensional e para o tridimensional, percebendo a necessidade de uma definição abstrata.

Comprovamos que a Geometria Dinâmica, nesse texto também retratada como Geometria em movimento, possibilitada pelo uso do software Winplot, favorece a visualização, a qual leva ao desenvolvimento do pensamento geométrico. Isso foi evidenciado por meio da superação das dificuldades apresentadas pelos estudantes, como: identificação dos eixos interceptos às superfícies, dos octantes aos quais a superfície ocupava, relação entre as equações e figuras, utilização de parâmetros para generalização de equações de superfícies ou de famílias dessas e o esboço da figura. A análise detalhada das respostas dadas pelos estudantes e os comportamentos apresentados na execução das tarefas nos trouxeram essas evidências; os discentes tiveram a oportunidade de descrever suas ideias, testá-las, refletir sobre elas e depurálas. Por exemplo, nas atividades relacionadas à superfície de revolução, os estudantes leram as definições apresentadas no material, plotaram as superfícies no software Winplot e foram motivados a refletir sobre elas, fazendo o registro das reflexões. Apresentamos um recorte de uma das atividades realizadas.

\section{QUADRO 3: sequência de atividades}

Trace no Winplot, utilizando a janela 3-Dim, o gráfico da função definida implicitamente pela equação: $\frac{x^{2}}{4}+\frac{y^{2}}{4}+\frac{z^{2}}{9}=1$, e responda:

a) O que se observa na equação quanto aos seus parâmetros?

b) Quais são as seções transversais obtidas pelos planos z $=0, z=2, z=6$ ? (Plote os planos usando equações explícitas.)

Observação: toda esfera ou esferoide é superfície de revolução.

c) Na esfera, as seções transversais são de que tipo?

d) Das equações abaixo, quais representam superfícies de revolução?
a)( ) $4 x^{2}+y^{2}+z^{2}=1$
d)( ) $2 x^{2}+4 y^{2}+z^{2}=1$
b)( ) $x^{2}+y^{2}-8 z^{2}=2$
e)( ) $x^{2}+5 y^{2}+5 z^{2}=25$
c)( ) $\mathrm{z}=x^{2}+y^{2}$
f) $\left(\right.$ ) $x^{2}+y^{2}+z^{2}=16$

f) Plote os gráficos acima no Winplot, observando as curvas de níveis. Registre suas observações.

\section{Fonte: Dados da pesquisa}

Apresentamos, na Figura 5, três protocolos realizados pelos estudantes em uma atividade que solicitava o esboço de um paraboloide elíptico. As instruções foram apresentadas da seguinte forma. 
QUADRO 4: sequência de atividades

Trace o paraboloide, de equação $\frac{x^{2}}{4}+\frac{y^{2}}{9}=\frac{z}{1}$ a partir de suas seções transversais:

a) Esboce as seguintes parábolas nos planos coordenados: $y=z^{2} ; z=x^{2}$

b) Esboce a elipse determinada pelo gráfico da função definida implicitamente pela equação $\frac{x^{2}}{4}+\frac{y^{2}}{9}=1$ no plano $z=5$.

d) Com as seções transversais dadas, monte o paraboloide num mesmo sistema de coordenadas.

\section{Fonte: Dados da pesquisa}

Verificamos que, de um esboço para o outro, os níveis de acertos aumentaram, sendo que o primeiro e o segundo esboços retratam que os estudantes, apesar de não terem realizado perfeitamente o esboço da superfície, delinearam as seções transversais, apenas não conseguiram relacionar as representações geométricas. No caso do terceiro esboço, o estudante conseguiu identificar as seções transversais e relacioná-las, geometricamente, para a construção da superfície, conforme ilustrado na Figura 5.

FIGURA 5: protocolos extraídos dos cadernos de atividades de três dos estudantes.

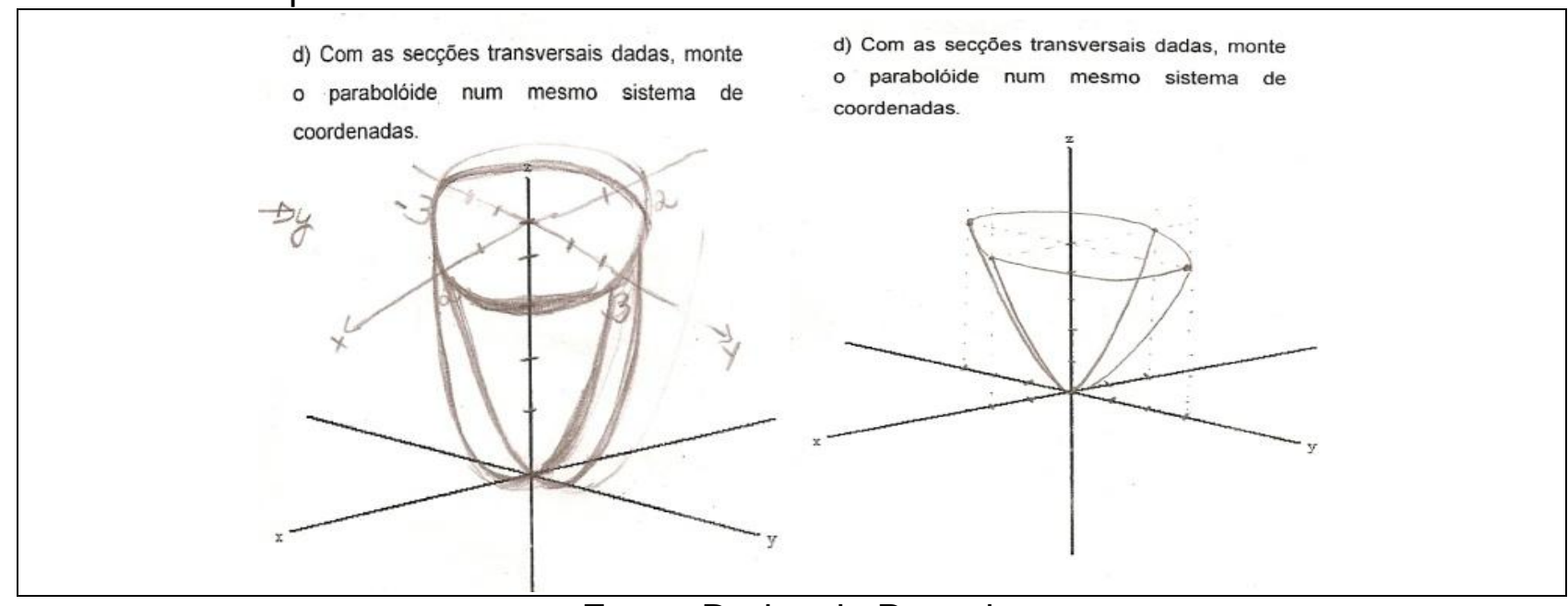

Fonte: Dados da Pesquisa

A seguir, apresentamos na Figura 6, algumas superfícies que foram plotadas pelos estudantes no software Winplot: 
FIGURA 6 - Representações gráficas das quádricas: Esfera de equação $\frac{x^{2}}{4}+\frac{y^{2}}{4}+\frac{z^{2}}{4}=1$; Esferoide de equação $\frac{x^{2}}{4}+\frac{y^{2}}{4}+\frac{z^{2}}{9}=1$, seccionado pelo plano $z=0$; Paraboloide de equação $4 z=x^{2}+y^{2}$, respectivamente.

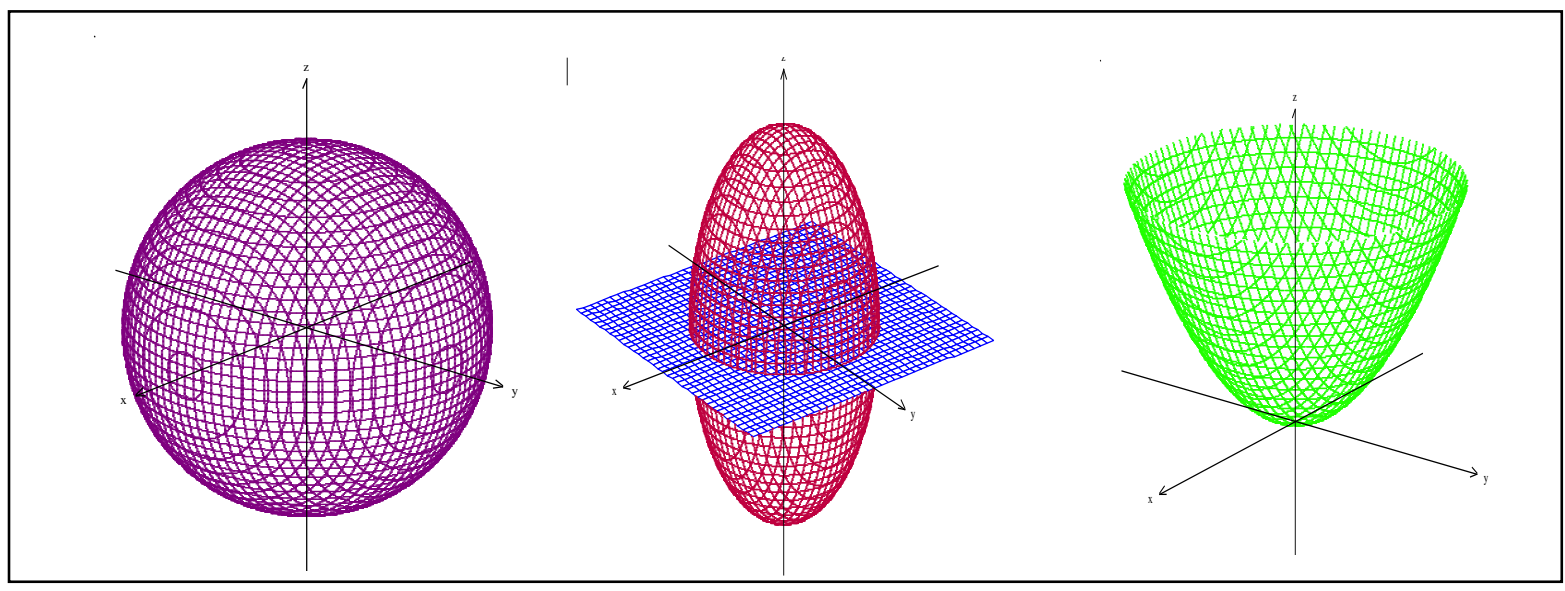

Fonte: Software Winplot

A articulação entre as representações algébrica e geométrica contribuíram para o desenvolvimento do processo de ensino dos tópicos em estudo, visto que as atividades abordavam questões relativas à análise dos aspectos algébricos e geométricos das superfícies em estudo, de forma que o foco na representação algébrica da superfície pudesse facilitar a compreensão de sua representação geométrica e vice-versa.

Durante a socialização do desenvolvimento das atividades, houve a interação entre professor-aluno e aluno-aluno. Como exemplo, observamos que uma dificuldade apresentada por um dos estudantes foi sanada pela intervenção de um colega, qual seja: um estudante manifestou que ainda estava com dúvidas com relação à visualização dos octantes, então um de seus colegas plotou os três planos coordenados $x z, y z, x y$ no Winplot, chamando a atenção para o que havia conseguido como resultado. Os dois conversaram sobre a representação geométrica visualizada na tela do computador, fazendo uma relação com a numeração dos octantes. Dessa forma, houve um maior entendimento para ambos.

A seguir, destacamos na Figura 7, a imagem obtida e utilizada pelos estudantes ao plotarem os planos paralelos aos planos coordenados. 
FIGURA 7 - Planos coordenados $x z, y z, x y$.

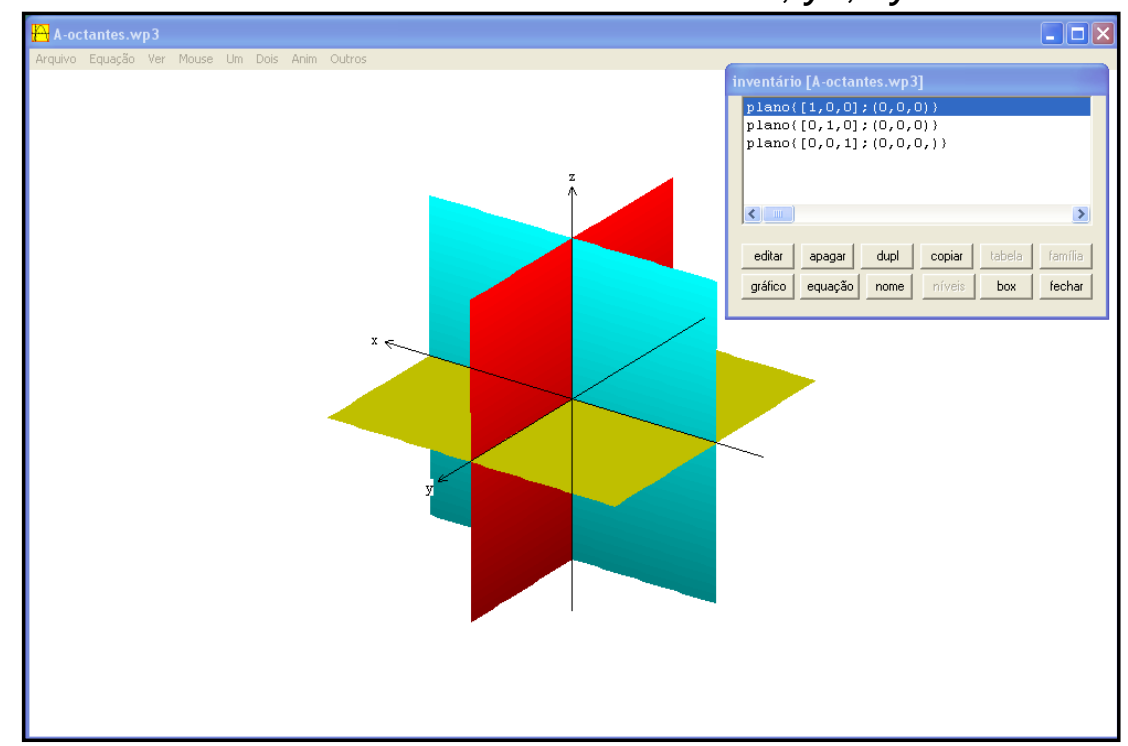

Fonte: Software Winplot.

Na Figura 8, apresentada abaixo, registramos um dos momentos de interação entre os estudantes.

FIGURA 8 - Estudantes realizando as atividades.

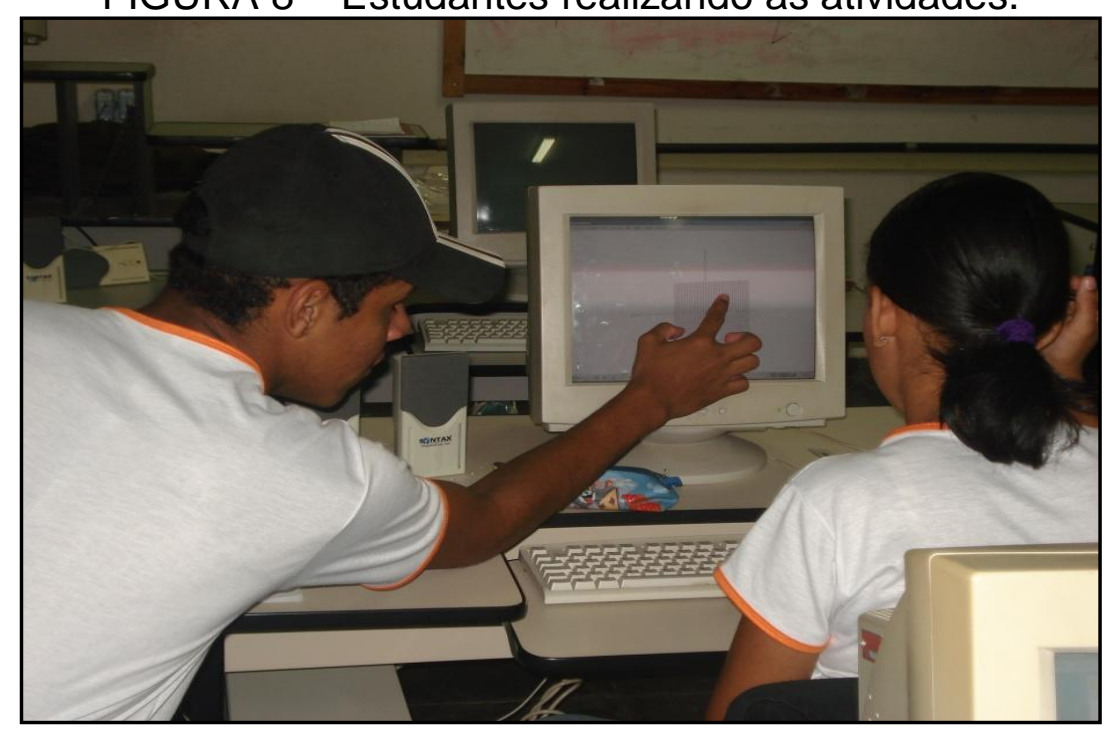

Fonte: Dados da Pesquisa

\section{Considerações finais}

Verificamos que, ao tratar a informação figural, os estudantes, sujeitos de nossa pesquisa, de uma forma geral, conseguiram entender conceitos geométricos relacionados com as superfícies em estudo, por meio da análise algébrica e também por meio das representações em termos visuais.

O saber-fazer, explorado em diversas situações e com diferentes superfícies, relacionando a equação (álgebra) à figura (geometria), favoreceu o desenvolvimento do pensamento relacional e uma melhor compreensão conceitual em Geometria Analítica, a qual integra álgebra com geometria, equação com a figura. 
Segundo Frota e Couy (2009), a visualização faz parte do fazer matemática, junto à intuição, abstração, dentre outras habilidades, o que conseguimos pela diversificação das atividades nessa investigação. Ainda, a utilização das seções transversais das superfícies contribuiu para a compreensão dessas, uma vez que o estudante parte da representação plana para a espacial. Isso fez com que a dificuldade de visualizar e esboçar gráficos em três dimensões fosse sendo minimizada ao longo das atividades.

Ao tratar da formação profissional de professores, podemos fazer a seguinte reflexão: para que se preocupar com tecnologias que colaborem para o ensino e uma aprendizagem mais eficazes? Não basta o domínio do conteúdo? Como aliar os recursos tecnológicos atuais com o ensino e com a aprendizagem? A nossa metodologia vai ao encontro dessas reflexões ao estabelecer a interação entre as mídias "software com lápis e papel", quando solicitamos a construção do esboço no papel antes de plotar as figuras pelo software, ocorrendo, algumas vezes, por alguns estudantes, a inversão da ordem de execução dessa tarefa, o que na nossa avaliação, contribuiu, mesmo assim, para melhoria da capacidade de visualização e do trabalho com pensamento geométrico.

Este trabalho, que se pautou num movimento da apresentação de conteúdo e construção do conhecimento relacionado, trazendo a metodologia do esboço das superfícies com as seções transversais e as curvas de níveis em um espaço de prática e experimentação, definiu uma série de itinerários e passos com que o estudante trabalhou e, dessa forma, pelos resultados alcançados, foi obtida uma aprendizagem mais efetiva.

\section{Referências}

BAIRRAL, Marcelo de Almeida. Tecnologias da Informação e Comunicação na formação e Educação Matemática. 2. ed. Rio de Janeiro: Editora da UFRRJ, 2012.

BORBA, Marcelo de $\mathrm{C}$. et al. Fases das tecnologias digitais em Educação

Matemática: Sala de aula e internet em movimento. 1. ed. BH: Autêntica Editora, 2014.

DUVAL, Raymound. Registros de representação semiótica e funcionamento cognitivo do pensamento. Tradução de Méricles Tadeu Moretti. REVEMAT: Revista Eletrônica de Educação Matemática. Florianópolis, v. 07, n. 2, 2012, p.266-297.

FERREIRA, Lúcia Helena da Cunha. Desenvolvimento do pensamento geométrico com visualização de figuras espaciais por meio da metodologia de oficinas. 2010. 137f. Dissertação (Mestrado em Ensino de Ciências e Matemática) - Pontifícia Universidade Católica de Minas Gerais. Belo Horizonte, 2010.

FROTA, Maria Clara Rezende; COUY, Laís. Estratégias para o ensino-aprendizagem de funções com um foco no Pensamento Visual. In: SEMINÁRIO INTERNACIONAL DE PESQUISA EM EDUCAÇÃO MATEMÁTICA, IV, Brasília, 2009. Anais do IV SIPEM. Brasília: SBEM, 2009. p. 1-20.

GALVÃO, Maria Elisa Esteves Lopes; COSTA, Nielce Meneguelo Lobo da; PRADO, Maria Elisabette Brizola Brito. Construção de funções a partir de problemas geométricos: uma abordagem investigativa. Revista de Ensino de Ciências e Matemática - REnCiMa, v.8, n.2, p.39-57, 2017. 
GODINO, Juan Dias; BATANERO, Carmen; FONT, Vicenç. The onto-semiotic approach to research in mathematics education. ZDM - The International Journal on Mathematics Education, v. 39, n. 1-2, p. 127-135, mar. 2007.

GONÇALVES, Jamille Santana; LANDO, Janice Cássia. O ensino de Geometria, em escolas públicas, na cidade de Jequié - Bahia. Eventos Pedagógicos, Sinop, v. 3, n. 3, p. 363-389, ago./dez. 2012.

GRAVINA, Maria Alice. Geometria Dinâmica: uma nova abordagem para o aprendizado da Geometria. In: Simpósio Brasileiro de Informática na Educação, VII, Belo Horizonte, 1996. Anais do VII SBIE. Belo Horizonte, 1996, p. 1-13.

MELO, Enaldo Vieira de; FIREMAN, Elton Casado. Ensino e aprendizagem de funções trigonométricas por meio do software GeoGebra aliado à modelagem matemática.

Revista de Ensino de Ciências e Matemática - REnCiMa, v.7, n.5, p. 12-30, 2016.

VAN HIELE, P. M. El problema de la comprensión: en conexión con la comprensión de los escolares en el aprendizaje de la geometría. 1957. Tesis (Doctorado en Matemáticas y Ciencias Naturais) - Universidad Real de Utrecht. Utrecht, 1957.

VILLARREAL, Mônica Ester. 0 pensamento matemático de estudantes universitários de Cálculo e Tecnologias Informáticas. 1999. Tese (Doutorado em Educação Matemática) - Instituto de Geociências e Ciências Exatas, Universidade Estadual Paulista. Rio Claro.

ZABALA, Antoni. A Prática Educativa: unidades de análise. In: ZABALA, Antoni. A prática educativa. Porto Alegre: ArtMed Editora, 1998. 